\title{
Deflazacort-Induced Erythema Multiforme Exudativum Successfully Treated With a Single Dose of Etanercept
}

Trujillo-Trujillo MJ ${ }^{1}$, González-Mancebo E ${ }^{1}$, Gandolfo-Cano $\mathrm{M}^{1}$, Mohedano-Vicente $\mathrm{E}^{1}$, Martínez-Morán $\mathrm{C}^{2}$

${ }^{1}$ Allergy Unit Hospital Universitario de Fuenlabrada, Fuenlabrada, Spain

${ }^{2}$ Dermatology Department Hospital Universitario de Fuenlabrada, Fuenlabrada, Spain

J Investig Allergol Clin Immunol 2018; Vol. 28(5): 338-339 doi: 10.18176/jiaci.0277

Key words: Delayed hypersensitivity. Deflazacort. Erythema multiforme exudativum. Treatment.

Palabras clave: Hipersensibilidad retardada. Deflazacort. Eritema exudativo multiforme. Tratamiento.

Corticosteroids can cause immediate and delayed hypersensitivity reactions, with a much higher prevalence in the case of delayed reactions [1]. The corticosteroids most frequently involved in delayed reactions are dexamethasone, betamethasone, and triamcinolone acetonide [2]. Reports of hypersensitivity to deflazacort are rare and include maculopapular rash, acute exanthematous pustulosis, and toxic epidermal necrolysis (TEN) [3-5]. No cases of deflazacort-induced erythema multiforme exudativum (EME) have been reported.

Severe drug-induced delayed reactions, such as TEN or EME, may be extremely difficult to treat.

Etanercept, a TNF blocker, has been used successfully in the treatment of TEN [6-10]. While the pathogenesis of TEN is unclear, it was observed that activated T cells secrete large amounts of TNF- $\alpha$ and interferon $\gamma$, resulting in apoptosis of keratinocytes [7]. Etanercept blocks this inflammatory pathway via inhibition of TNF.

We present a case of EME caused by deflazacort that was successfully treated with a single dose of etanercept.

A 45-year-old man with no significant personal history came to the emergency department with a 5-day history of erythematous-violaceous rash characterized by infiltrated papules on the scalp, face, neck, trunk, and upper limbs. He also presented with palpebral and labial edema accompanied by erosions on the oral mucosa and a sore throat. Four days previously, he had finished a course of oral amoxicillinclavulanic acid ( $875 \mathrm{mg}$ tid) and loratadine after nasal surgery, although he continued taking deflazacort (30 mg per day). After admission, he was unsuccessfully treated with a high dose of systemic methylprednisolone. Eosinophilia was not present, and no other organs or systems were involved. Tests were performed to rule out infections caused by Epstein-Barr virus, cytomegalovirus, human immunodeficiency virus, hepatitis viruses, and Mycoplasma pneumoniae.

Because of the rapidly spreading rash and worsening of the oral erosions, 2 cutaneous biopsies were performed and 
confirmed the suspected diagnosis of EME. Given recent reports of successful therapy with etanercept in TEN, a single subcutaneous dose of etanercept $(50 \mathrm{mg})$ was administered.

Two days later, the patient was discharged with complete recovery of his skin lesions.

Four months later, the results of patch tests with amoxicillin-clavulanic acid, loratadine, and deflazacort were negative. Prick tests with loratadine and deflazacort and prick and intradermal tests with amoxicillin and amoxicillinclavulanic acid with immediate and delayed readings were also negative.

Of all the drugs involved, amoxicillin was the most suspicious cause of EME; therefore, we decided to perform oral challenge tests with the other drugs involved. We started with deflazacort. Twelve hours after a cumulative dose of $37.5 \mathrm{mg}$ the patient developed red macules on his forearms and armpits, burning erythematous rash with white macules on his palms and soles, and mild upper lip edema. A single dose of etanercept was administered. Progression of the rash was controlled, and the skin healed completely after 2 days.

An oral challenge test and a 5-day course of amoxicillinclavulanic acid and loratadine were well tolerated.

We report the case of a patient who developed a delayed reaction to deflazacort in which 2 skin biopsies confirmed the diagnosis of EME. Previous reports of delayed hypersensitivity to deflazacort included maculopapular rash, TEN, and acute generalized exanthematous pustulosis [3-5]. The efficacy of TNF blockers in the treatment of TEN has been demonstrated in recent years [6-10], although no cases of EME successfully treated with this drug have been reported to date.

We present a case of EME due to deflazacort, a serious drug reaction that has not been previously reported with this corticosteroid. This is the first case of EME successfully treated with etanercept to date.

The current report highlights the usefulness of etanercept for treatment of EME, a severe drug reaction, and may be taken into account when other treatments fail.

\section{Funding}

The authors declare that no funding was received for the present study.

\section{Conflicts of Interest}

The authors declare that they have no conflicts of interest. systemic allergic dermatitis and literature review. Contact Dermatitis. 2016;75:54-6.

4. Pacheco D, Travassos AR, Antunes J, Silva R, Marques MS. Allergic hypersensitivity to deflazacort. Allergol Immunopatol. 2013:41:352-4.

5. Navarro A, Elizalde J, Boto B, Pujol E. Toxic epidermal necrolysis in a patient treated with high doses of deflazacort. Med Clin (Barc). 1996;106:599.

6. Didona D, Paolino G, Gargovich S, Caposiena Caro RD, Didona B. Successful use of etanercept in a case of toxic epidermal necrolysis induced by rituximab. J Eur Acad Dermatol Venereol. 2016;30(10):83-4.

7. Paradisi A, Abeni D, Bergamo F, Ricci F, Didona D, Didona B. Etanercept therapy for toxic epidermal necrolysis. J Am Acad Dermatol. 2014;71:278-83.

8. Napolitano N, Giampetruzzi AR, Didona D, Papi M, Didona B. Toxic epidermal necrolysis-like acute cutaneous lupus erythematosus successfully treated with a single dose of etanercept: report of three cases. J Am Acad Dermatol. 2013;69:303-5.

9. Gubinelli E, Canzona F, Tonanzi T, Raskovic D, Didona B. Toxic epidermal necrolysis successfully treated with etanercept. J Dermatol. 2009;36:150-3.

10. Famularo G, Di Dona B, Canzona F, Girardelli CR, Cruciani G. Etanercept for toxic epidermal necrolysis. Ann Pharmacother. 2007:41:1083-4.

Manuscript received March 1, 2018; accepted for publication May 23, 2018.

María Jesús Trujillo Trujillo Allergy Unit Hospital Universitario de Fuenlabrada Camino del Molino, 2

28942 Fuenlabrada (Madrid), Spain E-mail: mjtrujillo.hflr@salud.madrid.org

\section{References}

1. Soria A, Baeck M, Goossens A, Marot L, Duveille V, Derouaux $A S$, et al. Patch, prick or intradermal tests to detect delayed hypersensitivity to corticosteroids. Contact Dermatitis. 2011; 64:313-24.

2. Padial A, Posadas S, Alvarez J, Torres M-J, Alvarez JA, Mayorga $C$, et al. Nonimmediate reactions to systemic corticosteroids suggest an immunological mechanism. Allergy. 2005;60:66570.

3. Bianchi L, Hansel K, Antonelli E, Bellini V, Rigano L, Stingeni L. Deflazacort hypersensitivity: a difficult-to-manage case of 